\title{
A simple model of mergers and innovation*
}

\author{
Giulio Federico, ${ }^{\dagger}$ Gregor Langus $^{\ddagger}$ and Tommaso Valletti ${ }^{\S}$
}

May 29, 2017

\begin{abstract}
We analyze the impact of a merger on firms' incentives to innovate. We show that the merging parties always decrease their innovation efforts post-merger while the outsiders to the merger respond by increasing their effort. A merger tends to reduce overall innovation. Consumers are always worse off after a merger. Our model calls into question the applicability of the "inverted-U" relationship between innovation and competition to a merger setting.
\end{abstract}

Keywords: Innovation, R\&D, Mergers

JEL: D43, G34, L40, O30

\section{Introduction}

Innovation is a critical determinant of long-run growth and welfare. Competition policy should therefore seek to prevent mergers that reduce innovation while allowing those with a positive impact on innovation, through the appropriate use of merger control.

Despite its policy relevance, the theoretical link between mergers and innovation has not been studied extensively in the economic literature. Several papers consider the relationship between some measure of competition and innovation (e.g., Aghion et al. (2001), Aghion et al. (2005), Vives (2008), Lopez and Vives (2016)), sometimes finding an "inverted-U" relationship.

${ }^{*}$ We thank Daniel Coublucq, Cyril Hariton, Massimo Motta and Yossi Spiegel for useful discussions and comments. The opinions expressed in this paper are those of the authors alone and do not represent the views of any institution they are affiliated to.

$\dagger$ European Commission, giulio.federico@ec.europa.eu

$\ddagger$ European Commission, gregor.langus@ec.europa.eu

${ }^{\S}$ Corresponding author. European Commission, Imperial College London and CEPR, t.valletti@imperial.ac.uk 
These papers, however, do not explicitly consider the case of horizontal mergers. Similarly, earlier work on stochastic patent races (e.g., as surveyed by Reinganum (1989)) considers the relationship between the number of competitors and the rate of innovation, but does not actually model the impact of a merger between competing innovators. ${ }^{1}$ Therefore, policy implications for merger control are difficult to draw from this work.

This paper examines the impact of a merger on innovation by focusing on some of the basic underlying principles. A merger between competitors affects the incentives to innovate through two channels (absent efficiencies). The first channel relates to the (negative) externality that innovation by one firm has on its rival firms (see, e.g., Farrell and Shapiro (2010)). A merger allows the merging parties to partially internalize this innovation externality and thus it lowers the incentives to innovate for the merged firm. The second channel relates to product market competition. This is relaxed after the merger so that profits both when firms do not innovate, and when they do, increase. This effect is potentially ambiguous (as it has been recognized in the literature, e.g., Gilbert (2006) and Baker (2007)), and might in principle offset the first channel. This paper sets up a highly stylized model of a merger in an industry where innovation plays a key role, incorporating the two main channels for merger-induced innovation effects. It then provides some insight on the likely net effect of a merger on innovation (and consumer welfare). The model considers the case of stochastic product innovation (as opposed to process innovation, which has been more extensively considered in the literature; see, e.g., Vives (2008) and Lopez and Vives (2016)).

In the model, absent innovation firms do not make any profits. This implies that innovation does not cannibalize any pre-existing profits and that the product market competition channel described above can only act to promote innovation. This is a conservative feature of the model in terms of its predictions about the likely impact of a merger on innovation incentives (from the perspective of merger control). As there are no merger-induced efficiencies in the model, the effects on innovation incentives are based entirely on changes in competition between the merging parties. The paper is related to ongoing work based on a richer set of models, with explicit demand specifications (Federico et al. (2017)). The more general model enables us to take into account the impact of a merger on pre-innovation profits, and hence provides a more complete assessment of the effects of a merger on the incentives to innovate.

\footnotetext{
${ }^{1}$ This point is also made by Shapiro (2012). A notable recent exception is a model of Motta and Tarantino (2016), which considers the impact of a merger on deterministic cost-reducing investment (process innovation). See also Chen and Schwartz (2013) who discuss a merger to monopoly, but do not model competition at the innovation stage.
} 


\section{The model}

We consider a two-stage game played by $n>2$ symmetric firms. Before the merger, each firm has a single research lab. In the first stage, firms exert some costly effort in their labs $C\left(w_{i}\right)$, with $C(0)=0, C^{\prime}>0, C^{\prime \prime}>0$, $C^{\prime}(0)=0$ and $\lim _{w_{i} \rightarrow 1} C^{\prime}\left(w_{i}\right)=\infty$. The effort level determines the probability $w_{i} \in[0,1)$ that the lab will successfully innovate - discover a new (homogenous) product. Probabilities of discovery are i.i.d. across labs and there can be $2^{n}$ discovery outcomes - each outcome representing a different profile of successes in the discovery stage. In the second stage firms observe the outcomes of the first stage and receive payoffs. To simplify our analysis, we assign payoffs to the outcomes as follows. If a firm did not discover the product, it gets a zero payoff. If only one firm was successful, it gets a prize normalized to 1 . If two competing firms successfully discovered the product, each gets a prize worth $\delta \ll 1$. If three or more competing firms successfully introduce the product, we assume that competition upon the commercialization of the discovery is so strong that all firms get a zero payoff. Note that $\delta=0$ corresponds to a standard homogeneous good Bertrand case, whereas firms can get $\delta>0$ to the extent they can coordinate their pricing (and coordination is not effective when 3 or more firms successfully innovate). Unless stated explicitly, our analytical proofs are all conducted for very small values of $\delta$. We then demonstrate some of our results numerically for higher values of $\delta$.

\section{$2.1 \quad$ Pre-merger}

We solve the game backwards. In the last stage, payoffs are dictated by the number of successful innovators, as described above. Take a situation where all firms $j \neq i$ behave in the same way. In the first stage firm $i$ solves

$$
\max _{w_{i}} \Pi_{i}=w_{i}\left[\left(1-w_{j}\right)^{n-1} \cdot 1+(n-1) w_{j}\left(1-w_{j}\right)^{n-2} \cdot \delta\right]-C\left(w_{i}\right),
$$

Eq. (1) says that firm $i$ gets the full prize if it is the only inventor (hence no firm $j \neq i$ is successful), while it gets a fraction $\delta$ if exactly one rival is successful in discovery (there are $n-1$ such combinations). The corresponding FOC is

$$
\left(1-w_{j}\right)^{n-1}+(n-1) w_{j}\left(1-w_{j}\right)^{n-2} \delta=C^{\prime}\left(w_{i}\right),
$$

and the SOC is always satisfied. A symmetric equilibrium with $w_{i}=w_{j}=w^{*}$ is characterized by

$$
\left(1-w^{*}\right)^{n-2}\left[1-w^{*}+(n-1) \delta w^{*}\right]=C^{\prime}\left(w^{*}\right) .
$$


As the RHS in (2) is strictly increasing from 0 to $\infty$ and the LHS is strictly decreasing from a finite value to 0 in $w^{*}$ (at least for small values of $\delta$ ), a solution to the previous equation exists and is unique. Also note that $w^{*}$ increases as $\delta$ increases. In particular, for later use, we calculate by totally differentiating $(2)$

$$
\left.\frac{\partial w^{*}}{\partial \delta}\right|_{\delta=0}=\frac{(n-1) w^{*}}{n-1+\left(1-w^{*}\right)^{2-n} C^{\prime \prime}\left(w^{*}\right)}>0 .
$$

\section{$2.2 \quad$ Merger}

Assume w.l.o.g. that two firms, firm 1 and 2, merge their research labs and form a new firm that we denote as $M$. Because of decreasing returns to effort, firm $M$ will still put effort in both labs, and will set $w_{1}=w_{2}=w_{M}$. In the first stage, when all firms $j \neq M$ behave in the same way, the merged firm maximizes

$$
\max _{w_{M}} \Pi_{M}=\left[1-\left(1-w_{M}\right)^{2}\right]\left[\left(1-w_{j}\right)^{n-2}+(n-2) w_{j}\left(1-w_{j}\right)^{n-3} \delta\right]-2 C\left(w_{M}\right) .
$$

Eq. (4) highlights the price coordination effect for the merging parties. If firm $M$ is the only successful innovator - one or both of its labs are the only ones that successfully discovered - it will get the whole prize. It gets $\delta$ in case only one rival successfully makes the same discovery (even if firm $M$ has been successful with both labs). In other words, whenever the two labs are successful in discovery, firm $M$ perfectly coordinates its price decisions between its two (identical) products.This is also equivalent to the assumption-reasonable in this setting, given homogenous products - that only one of two successful discoveries of the product is commercialized by the same firm. The FOC w.r.t. $w_{M}$ is

$$
\left(1-w_{M}\right)\left(1-w_{j}\right)^{n-3}\left[1-w_{j}+(n-2) \delta w_{j}\right]=C^{\prime}\left(w_{M}\right) .
$$

We thus establish our first result.

Proposition 1 The merged firm decreases effort in each lab compared to the situation pre-merger for all $\delta>0$.

Proof. Note that we can concentrate on the probability of success, as this is monotonically related to effort via the cost function. We evaluate (5) at the pre-merger equilibrium given by (2). If $w_{M}=w_{j}=w^{*}$, then (5) reduces to $-\delta w^{*}\left(1-w^{*}\right)^{n-2}<0$ for all $\delta>0$. Hence $w_{M}<w^{*}$. 
What about the firms outside the merger? For firm $i \neq M$, the expression of the profit is now (again, we consider when all firm $j \neq M, i$ behave in the same way)

$$
\begin{aligned}
\max _{w_{i}} \Pi_{i}=w_{i}\left\{\left(1-w_{M}\right)^{2}\left(1-w_{j}\right)^{n-3}+\left[1-\left(1-w_{M}\right)^{2}\right]\left(1-w_{j}\right)^{n-3} \delta+\right. \\
\left.+(n-3) w_{j}\left(1-w_{M}\right)^{2}\left(1-w_{j}\right)^{n-4} \delta\right\}-C\left(w_{i}\right) .
\end{aligned}
$$

The corresponding FOC is

$\left(1-w_{j}\right)^{n-4}\left[\left(1-w_{M}\right)^{2}\left(1-w_{j}\right)+w_{M}\left(2-w_{M}\right)\left(1-w_{j}\right) \delta+(n-3) w_{j}\left(1-w_{M}\right)^{2} \delta\right]=C^{\prime}\left(w_{i}\right)$.

In equilibrium, all firms $j \neq M, i$ will behave symmetrically as firm $i$. Let us define

$$
\begin{aligned}
F O C_{i} \equiv\left(1-w_{i}\right)^{n-4}\left(1-w_{M}\right)\left[\left(1-w_{M}\right)\left(1-w_{i}\right)+\right. \\
\left.+2 w_{M}\left(1-w_{i}\right) \delta+(n-3) w_{i}\left(1-w_{M}\right) \delta\right]-C^{\prime}\left(w_{i}\right)=0 .
\end{aligned}
$$

We now calculate the reaction function from the total differential

$$
\frac{\partial F O C_{i}}{\partial w_{i}} d w_{i}+\frac{\partial F O C_{i}}{\partial w_{M}} d w_{M}=0 .
$$

In particular, around $\delta=0\left(\text { when } w_{i}=w_{M}=w^{*}\right)^{2}$ we obtain

$$
\left.\frac{\partial w_{i}}{\partial w_{M}}\right|_{\delta=0}=-\frac{2}{n-3+\left(1-w^{*}\right)^{2-n} C^{\prime \prime}\left(w^{*}\right)}<0 .
$$

Efforts are strategic substitutes. While the merger decreases efforts of the insiders, it increases efforts of the outsiders. In principle, the effect on total effort could be indeterminate. Although total effort as such is not a proper welfare measure in our setting, as what matters is how effort is distributed across the various discovery outcomes, it is still of some interest to look at the impact of the merger on the effort spent by firms overall. ${ }^{3}$ Our next result shows that the result from the insiders always prevails in a concentrated industry, while the opposite holds true in a fragmented industry, for $\delta$ close to zero. ${ }^{4}$

\footnotetext{
${ }^{2}$ This follows immediately as, at $\delta=0$, before the merger, the symmetric equilibrium is characterized by $(2),\left(1-w^{*}\right)^{n-1}=C^{\prime}\left(w^{*}\right)$. After the merger, (5) and (6) simplify respectively to $\left(1-w_{M}\right)\left(1-w_{j}\right)^{n-2}=C^{\prime}\left(w_{M}\right)$ and $\left(1-w_{i}\right)^{n-3}\left(1-w_{M}\right)^{2}=C^{\prime}\left(w_{i}\right)$. By simple inspection it can be verified that $w_{i}=w_{M}=w^{*}$.

${ }^{3}$ We consider the more canonical measure of consumer welfare which is used in merger reviews further below.

${ }^{4}$ We derive an additional result of interest. We analyze the impact that the merger has on one particular "bad" state, notably when there is no innovation at all in the whole industry. It turns out that this impact follows the same behavior as total effort. This is intuitive as probabilities are i.i.d. The result is proven formally in the Annex.
} 
Proposition 2 Total industry effort decreases after the merger iff $n$ is low enough.

Proof. The proof relies on the fact that efforts are invariant to the merger for $\delta=0$. Then we study the effect of a small increase in $\delta$ on total effort pre- and post-merger. Pre-merger, total effort is $E f f_{\text {pre }}=n C\left(w^{*}\right)$. From (2) we obtain

$$
\left.\frac{\partial E f f_{\text {pre }}}{\partial \delta}\right|_{\delta=0}=\left.n C^{\prime}\left(w^{*}\right) \frac{\partial w^{*}}{\partial \delta}\right|_{\delta=0}=\frac{n(n-1) w^{*} C^{\prime}\left(w^{*}\right)}{n-1+\left(1-w^{*}\right)^{2-n} C^{\prime \prime}\left(w^{*}\right)} .
$$

Similarly, total effort post-merger is $E f f_{\text {post }}=(n-2) C\left(w_{i}^{*}\right)+2 C\left(w_{M}^{*}\right)$. We apply Cramer's rule to the system of FOCs given by (5) and (6), and we calculate

$$
\begin{aligned}
\left.\frac{\partial E f f_{\text {post }}}{\partial \delta}\right|_{\delta=0}=\left.(n-2) C^{\prime}\left(w_{i}^{*}\right) \frac{\partial w_{i}^{*}}{\partial \delta}\right|_{\delta=0} & +\left.2 C^{\prime}\left(w_{M}^{*}\right) \frac{\partial w_{M}^{*}}{\partial \delta}\right|_{\delta=0}= \\
& =\frac{\left(n+\frac{1}{1-w^{*}}\right)(n-2) w^{*} C^{\prime}\left(w^{*}\right)}{n-1+\left(1-w^{*}\right)^{2-n} C^{\prime \prime}\left(w^{*}\right)} .
\end{aligned}
$$

As $\left(n+\frac{1}{1-w^{*}}\right)(n-2)<n(n-1)$ if and only if $n w^{*}<2$, we need to study the behavior of $n w^{*}$, where $w^{*}$ is implicitly defined by $\left(1-w^{*}\right)^{n-1}=C^{\prime}\left(w^{*}\right)$, with $\frac{\partial w^{*}}{\partial n}<0$. The function $n w^{*}$ is increasing without bounds in $n$. It starts from a minimum when $n=2$, where, as $w^{*}<1$, it must be $n w^{*}<2$. Hence there must be a threshold value of $n$, denoted as $\widehat{n}>2$, such that $\left.\frac{\partial E f f_{\text {post }}}{\partial \delta}\right|_{\delta=0}<\left.\frac{\partial E f f_{\text {pre }}}{\partial \delta}\right|_{\delta=0}$ iff $n<\widehat{n}$. Note that $\widehat{n}$ can be made arbitrarily large with a sufficiently high marginal cost $C^{\prime}\left(w^{*}\right)$. Hence $E f f_{\text {post }}<E f f_{\text {pre }}$ for small increases in $\delta$ iff $n<\widehat{n}$.

Is the merger profitable? To answer this question, we again use the fact that, at $\delta=0$, effort is invariant to the merger. Profits, however, are not invariant, since the merger allows a price coordination effect in case both labs are successful at innovating. Formally, evaluating (1) and (4) at $\delta=0$, when $w_{M}^{*}=w_{i}^{*}=w^{*}$, results in

$$
\left.\left(\Pi_{M}-2 \Pi_{i}\right)\right|_{\delta=0}=w^{* 2}\left(1-w^{*}\right)^{2-n}>0 .
$$

Since profits are continuous in $\delta$, the merger is profitable also for small positive values of $\delta$. We can summarize this result formally.

Proposition 3 The merger between firm 1 and firm 2 is profitable. 
We now briefly sketch an analysis of the effect of the merger on consumer surplus. Let us denote as $C S_{k}$ the consumer surplus in state $k$, where $k=0,1,2,3+$ denotes the number of firms that independently introduce innovations into product market. It is natural to assume that $C S_{0}=0$, as without innovation there is no market in our model. Conditional on at least one firm having innovated, price competition is weakest when $k=1$, and toughest when there are 3 or more successful firms $(k=3+)$. Thus it is also natural to posit $C S_{1}<C S_{2}<C S_{3+}$.

In the Annex, we show that, on top of the differences arising from changes in innovation efforts, the impact for consumers is due to the classic price coordination effect of the merging parties. Conditional on being successful with both labs, the merged entity shifts consumer surplus towards a "worse" state, e.g., from $C S_{2}$ to $C S_{1}$ (when both its labs are successful, and no one else is), or from $C S_{3+}$ to $C S_{2}$ (when both its labs are successful, and only one of its rivals also is). In particular, in the Annex we show that, as $\delta$ approaches zero

$$
\begin{aligned}
C S_{\text {post }}-C S_{\text {pre }}=w^{* 2}(1- & \left.w^{*}\right)^{n-2}\left(C S_{1}-C S_{2}\right)+ \\
& +(n-2) w^{* 3}\left(1-w^{*}\right)^{n-3}\left(C S_{3+}-C S_{2}\right)<0 .
\end{aligned}
$$

The expression shows how a merger harms consumer welfare even when, for $\delta=0$, it has no effect on innovation effort. ${ }^{5}$ If owned independently, whenever the two labs are successful in discovery, they produce competing products - this is not the case after the merger as firm $M$ will fully internalize its pricing decisions in product market competition. We stress that, after a merger, there is always a discontinuous change in the probability of bad states for consumers because of this effect. It affects only states $1,2,3+$, while it does not impact state 0 . The probability of state 0 is affected only by efforts (efforts clearly affect also the probabilities of other states). As the efforts do no change locally around $\delta=0$, the impact of the merger through effort will always be second-order compared to the main discrete jump coming from (7). Hence the negative effect on the merger extends for sure to small but positive values of $\delta$. We summarize below our findings for small values of $\delta$.

Proposition 4 Consumers are worse off after the merger.

We note that, from a total welfare perspective, the merger always creates an inefficiency in the allocation of effort, as starting from an (efficient) symmetric distribution of efforts among firms, the merger provides asymmetric incentives to exert effort between insiders and outsiders.

\footnotetext{
${ }^{5}$ In our setting, for $\delta=0$, product market competition between two independent innovators is as intense as competition between three or more innovators, so that there we have additionally that $C S_{2}=C S_{3+}$.
} 
We conclude our analysis by showing, in Figures 1 and 2, numerical results for the effect of the merger on effort and on consumer surplus for higher values of $\delta$ up to the highest possible value of $1 / 2$ (the figures are drawn for premerger $n=5$ and $n=10$ ). The figures confirm in particular all the analytical findings obtained in Proposition 1 and 4 around $\delta=0 .{ }^{6}$

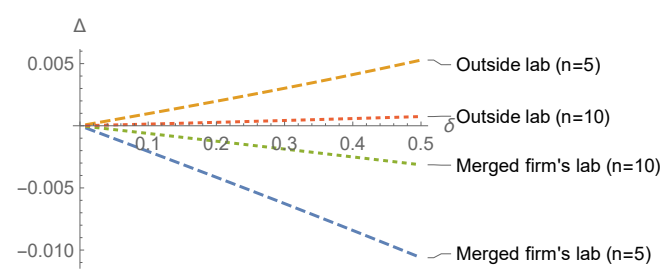

Figure 1: Difference $(\Delta)$ between post and pre-merger effort

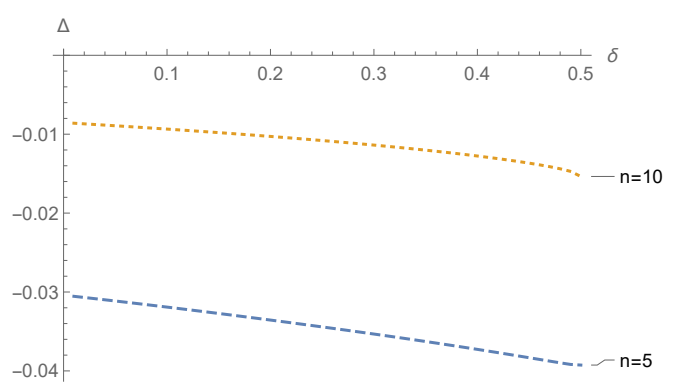

Figure 2: Difference $(\Delta)$ between post and pre-merger CS

\section{Conclusions}

We revisited the question of innovation and mergers. We used a very simple ad hoc model, yet rich enough to give some interesting results. We showed that the inverted-U relationship between innovation and some measure of competition does not have an immediate counterpart in a merger setting, at least insofar as the innovation output of the merged firm is concerned. We find that a merger reduces the incentives to innovate for the merging parties, absent efficiencies or spillover effects that would reduce appropriability $e x$ post. The main driver is a standard unilateral effect: prior to a merger, firms compete in innovation to drive customers away from rivals; after a merger, this cannibalization effect is internalized and innovation competition becomes muted. Of course, this is not the only effect, as the merging parties can also increase profitability ex post by coordinating their prices, which may give rise

\footnotetext{
${ }^{6}$ For the plots we assume $C\left(w_{i}\right)=-\log \left(1-w_{i}^{2}\right)$ that satisfies the assumptions of the model. We obtain consumer surplus $C S_{1}, C S_{2}$ and $C S_{3+}$ by further assuming a linear demand for a homogenous good, in particular $q(p)=2-p$, and zero marginal costs. Prices in states $k=1,2,3+$ are $p_{1}=1, p_{2}=1-\sqrt{1-2 \delta}$ and $p_{3+}=0$ so that profits per firm are indeed $1, \delta$ and 0 . Correspondingly $C S_{1}=\frac{1}{2}, C S_{2}=1+\sqrt{1-2 \delta}-\delta$ and $C S_{3+}=2$. In this example, the threshold value of Proposition 2 would be $\widehat{n}=30$. The welfare analysis with more general consumer preferences is tackled in our ongoing work (Federico et al., 2017).
} 
to additional incentives to innovate $e x$ ante. Yet, in our model the first effect of reduced innovation competition prevails. In fact, our ongoing work suggests that the mechanism highlighted here is quite strong and holds in more complex and realistic settings where firms compete by offering differentiated products (Federico et al., 2017). This suggests that the internalisation of the innovation externality remains the dominant driver of the impact of the merger on innovation incentives. We advocate for the academic community to pursue further this specific line of research about mergers and innovation.

\section{References}

[1] Aghion, Philippe, Cristopher Harris, Peter Howitt and John Vickers (2001), "Competition, Imitation and Growth with Step-by-Step Innovation", Review of Economic Studies, 68, 467-492.

[2] Aghion, Philippe, Nick Bloom, Richard Blundell, Rachel Griffith and Peter Howitt (2005), "Competition and innovation: an inverted-U relationship", Quarterly Journal of Economics, 120(2), 701-728.

[3] Baker, Jonathan (2007), "Beyond Schumpeter vs. Arrow: How Antitrust Fosters Innovation", Antitrust Law Journal, 74, 575-602.

[4] Chen, Yongmin and Marius Schwartz (2013), "Product innovation incentives: monopoly vs. competition", Journal of Economics \& Management Strategy, 22(3), 513-528.

[5] Farrell, Joseph and Carl Shapiro (2010), "Antitrust Evaluation of Horizontal Mergers: An Economic Alternative to Market Definition", The B.E. Journal of Theoretical Economics, 10(1).

[6] Federico, Giulio, Gregor Langus and Tommaso Valletti (2017), "Mergers and Innovation: An Economic Framework", mimeo.

[7] Gilbert, Richard (2006), "Looking for Mr. Schumpeter: Where are we in the competition-innovation debate?", in Adam Jaffe, Josh Lerner and Scott Stern (eds.), Innovation Policy and the Economy, Volume 6, 159215, University of Chicago Press.

[8] Lopez, Angel and Xavier Vives (2016), "Cross-ownership, R\&D Spillovers, and Antitrust Policy", CESifo working paper 5935.

[9] Motta, Massimo and Emanuele Tarantino (2016), "The Effect of a Merger on Investments", CEPR DP11550. 
[10] Reinganum, Jennifer F. (1989), "The Timing of Innovation: Research, Development, and Diffusion", in Richard Schmalensee and Robert D. Willig (eds.), Handbook of Industrial Organization, Volume 1, 849-908, Elsevier.

[11] Shapiro, Carl (2012), "Competition and innovation. Did Arrow hit the bull's eye?", in Josh Lerner and Scott Stern (eds.), The Rate and Direction of Inventive Activity Revisited, 361-404, University of Chicago Press.

[12] Vives, Xavier (2008), "Innovation and Competitive Pressure", Journal of Industrial Economics, 56(3), 419-469.

\section{Annex}

In this Annex we first show that the probability of no innovation taking place in the industry follows the behavior of total effort described in Proposition 2. Then we provide the proof of Proposition 4.

Corollary 5 The merger increases the probability that there is no innovation when the industry is concentrated.

Proof. Before the merger, the no innovation state happens with probability $\operatorname{Pr}_{\text {pre }}=\left(1-w^{*}\right)^{n}$. After the merger, there is no industry innovation with probability $\operatorname{Pr}_{\text {post }}=\left(1-w_{M}^{*}\right)^{2}\left(1-w_{i}^{*}\right)^{n-2}$. The impact of a small increase in $\delta$, starting from $\delta=0$, before the merger is $\left.\frac{\partial \operatorname{Pr}_{p r e}}{\partial \delta}\right|_{\delta=0}=\left(1-w^{*}\right)^{n-1}\left[\left.n \frac{\partial w^{*}}{\partial \delta}\right|_{\delta=0}\right]$. After the merger, as at $\delta=0$ it is $w_{M}^{*}=w_{i}^{*}=w^{*}$, it is $\left.\frac{\partial \operatorname{Pr}_{\text {post }}}{\partial \delta}\right|_{\delta=0}=$ $\left.2\left(1-w_{M}^{*}\right)\left(1-w_{i}^{*}\right)^{n-2} \frac{\partial w_{M}^{*}}{\partial \delta}\right|_{\delta=0}+\left.(n-2)\left(1-w_{M}^{*}\right)^{2}\left(1-w_{i}^{*}\right)^{n-3} \frac{\partial w_{i}^{*}}{\partial \delta}\right|_{\delta=0}=$ $\left(1-w^{*}\right)^{n-1}\left[\left.2 \frac{\partial w_{M}^{*}}{\partial \delta}\right|_{\delta=0}+\left.(n-2) \frac{\partial w_{i}^{*}}{\partial \delta}\right|_{\delta=0}\right]$. Since at equilibrium $\left(1-w^{*}\right)^{n-1}=$ $C^{\prime}\left(w^{*}\right)$, it is exactly $\left.\frac{\partial \operatorname{Pr}_{\text {post }}}{\partial \delta}\right|_{\delta=0}-\left.\frac{\partial \operatorname{Pr}_{\text {pre }}}{\partial \delta}\right|_{\delta=0}=\left.\frac{\partial E f f_{\text {post }}}{\partial \delta}\right|_{\delta=0}-\left.\frac{\partial E f f_{\text {pre }}}{\partial \delta}\right|_{\delta=0}$. Thus the probability of the no innovation state follows the same behavior as total effort.

Proof of Proposition 4. Before the merger, denoting by $\operatorname{Pr}(k)$ the probability of occurrence of state $k$, expected consumer surplus takes the 
expression

$$
\begin{aligned}
& C S_{\text {pre }}=\sum_{k}^{2^{n}}\left(\begin{array}{l}
n \\
k
\end{array}\right) \operatorname{Pr}(k) C S_{k}= \\
&\left(1-w^{*}\right)^{n} C S_{0}+n w^{*}\left(1-w^{*}\right)^{n-1} C S_{1}+\frac{n(n-1)}{2} w^{* 2}\left(1-w^{*}\right)^{n-2} C S_{2}+ \\
& \quad+\left\{1-\left(1-w^{*}\right)^{n}\left[1+n \frac{w^{*}}{1-w^{*}}+\frac{n(n-1)}{2}\left(\frac{w^{*}}{1-w^{*}}\right)^{2}\right]\right\} C S_{3+} .
\end{aligned}
$$

After the merger, expected consumer surplus becomes

$$
\begin{aligned}
& C S_{\text {post }}=\underbrace{\left(1-w_{i}^{*}\right)^{n-2}\left(1-w_{M}^{*}\right)^{2}}_{p_{0}} C S_{0}+ \\
& +[\underbrace{2 w_{M}^{*}\left(1-w_{M}^{*}\right)\left(1-w_{i}^{*}\right)^{n-2}+(n-2) w_{i}^{*}\left(1-w_{i}^{*}\right)^{n-3}\left(1-w_{M}^{*}\right)^{2}}_{p_{1}}+\mathbf{w}_{M}^{* 2}\left(\mathbf{1}-\mathbf{w}_{\mathbf{i}}^{*}\right)^{n-2}] C S_{1}+ \\
& +\underbrace{\left\{w_{M}^{* 2}\left(1-w_{i}^{*}\right)^{n-2}+2(n-2) w_{M}^{*}\left(1-w_{M}^{*}\right)\left(1-w_{i}^{*}\right)^{n-3} w_{i}^{*}+\frac{(n-2)(n-3)}{2}\left(1-w_{M}^{*}\right)^{2}\left(1-w_{i}^{*}\right)^{n-4} w_{i}^{* 2}\right.}_{p_{2}}- \\
& \left.-\mathbf{w}_{M}^{* 2}\left(\mathbf{1}-\mathbf{w}_{i}^{*}\right)^{n-2}+(\mathbf{n}-\mathbf{2}) \mathbf{w}_{M}^{* 2} \mathbf{w}_{i}^{*}\left(\mathbf{1}-\mathbf{w}_{i}^{*}\right)^{n-3}\right\} C S_{2}+ \\
& +\left[1-p_{0}-p_{1}-p_{2}-(\mathbf{n}-\mathbf{2}) \mathbf{w}_{M}^{* 2} \mathbf{w}_{i}^{*}\left(\mathbf{1}-\mathbf{w}_{i}^{*}\right)^{n-3}\right] C S_{3+} .
\end{aligned}
$$

Conditional on being successful with both labs, the merged entity shifts consumer surplus towards a "worse" state, e.g., from $C S_{2}$ to $C S_{1}$ (when both its labs are successful, and no one else is, which happens with probability $w_{M}^{* 2}\left(1-w_{i}^{*}\right)^{n-2}$ ), or from $C S_{3+}$ to $C S_{2}$ (when both its labs are successful, and only one of its rivals also is, which happens with probability $(n-2) w_{M}^{* 2} w_{i}^{*}(1-$ $\left.w_{i}^{*}\right)^{n-3}$ ). This is emphasized in bold in the equation above. When $\delta=0$, $w_{M}^{*}=w_{i}^{*}=w^{*}$, and $p_{0}, p_{1}, p_{2}$ are equal to the corresponding pre-merger probabilities. Thus the expression for $C S$ simplifies so that we obtain (7). 